Engineering Sustainability Volume 167 Issue ES6

Educating engineers to embrace complexity and context

Byrne and Mullally

ice | proceedings
Proceedings of the Institution of Civil Engineers

Engineering Sustainability 167 December 2014 Issue ES6

Pages 241-248 http://dx.doi.org/10.1680/esu.14.00005 Paper 1400005

Received 10/02/2014 Accepted 24/07/2014

Published online 23/10/2014

Keywords: education \& training/social impact/

sustainability
ice

$\overline{\text { Institution of Civil Engineers }}$

\title{
Educating engineers to embrace complexity and context
}

Edmond P. Byrne MSc, MA, PhD

Senior Lecturer, School of Engineering, University College Cork, Ireland
Gerard Mullally MA, PhD

Lecturer, Department of Sociology, University College Cork, Ireland

Education represents a key intervention point in encouraging the emergence of a professional engineering ethos informed by a sustainability ethic. In terms of establishing an appropriate relationship between sustainability and education, many would contend that incorporating sustainability as merely add-on material to already overcrowded curricula is insufficient. Instead sustainability should actually be a leading principle for curricula. Traditional reductionist models of engineering education seek to extinguish context and uncertainty and reduce complexity across socio-economic and ecological domains. They therefore constitute a wholly inadequate response to the need for fit-for-purpose, twenty-first century graduates required to address broader sustainability issues. This paper presents research from an undergraduate module at University College Cork, Ireland. The module is aimed at developing students' conceptions of complexity, uncertainty, risk, context and ethics as foundational bases for productively engaging with sustainability. The paper also highlights some problematic issues.

\section{Introduction}

There is a realisation that what has been called a 'new engineer' is required for fit-for-purpose twenty-first century engineering in order to address the attendant challenges and crises around (un)sustainability that face contemporary society (Beder, 1998). This is a professional who recognises that values and ethics pervade all engineering practice, leaves hubristic illusions of control aside and embraces context, complexity, inherent uncertainty and risk (Bucciarelli, 2008). S/he recognises the 'deep sociotechnical complexities that are often at the heart of [engineering] "Grand Challenges"” while making "explicit the social and ethical responsibilities of engineers' (Herkert and Banks, 2012). Moreover, while they recognise the value of scientific and technological approaches in relation to contemporary societal challenges, the 'new engineer' acknowledges that technocentric approaches alone are incapable of achieving progress towards sustainable outcomes among inter-related complex social, techno-economic and ecological systems (Conlon, 2008). Such approaches need to be complemented by recognition of the importance of context and the presence of contingency and indeterminacy in these complex systems, and hence value the additional knowledge that can be provided by experiential and local knowledge and intuition.

This is a view consistent with one proposed across the domain of engineering education for sustainable development (EESD) over the past two decades. Such a view proposes the incorporation of sustainability within and across engineering programmes as a 'leading principle for curricula' to elicit a broader conception of the engineer (in contrast to incorporating content merely as 'add on' material to an already overcrowded curriculum) (Mulder et al., 2012). It also aligns with contemporary directions in the sociology of sustainable development (e.g. Baillie et al., 2013) and with education and pedagogical theory (e.g. Boud, 2000).

\section{Module description}

This paper reflects on the experiences of a first-year module on a (four-year) undergraduate engineering programme at University College Cork (UCC), Ireland which seeks to help facilitate the development of a fit-for-purpose twenty-first century engineer. The module (PE1006: professional engineering communication and ethics) is taken by engineering students across all four engineering programmes at UCC (civil and environmental, electrical and electronic, energy, and process and chemical). The four programmes incorporate varying degrees of material and ethos associated with sustainability across the respective programmes, with, for example, the chemical engineering students taking a 'Sustainability in process engineering' module in the third year, two 'Safety and environmental protection' modules in the third and fourth years and a final year capstone design project module in the fourth year, which entails a significant sustainability component (Fitzpatrick et al., 2013). The module includes contributions from academics across the school, including the lead author who is module coordinator and teaches half the module. The following learning outcomes are associated with this part of the module:

relate professional engineering practice to the ethics and ethos of the profession and the role of engineering in society

- understand the nature of complex, wicked problems and apply appropriate strategies for resolving such problems. 
Engineering Sustainability

Volume 167 Issue ES6
Educating engineers to embrace

complexity and context

Byrne and Mullally
Class contact time with the lead author comprises 12 teaching hours, eight hours of design/tutorial sessions and four hours of student assignment presentations around the following topics

role of engineering in society

wicked problems

a philosophy of engineering (historical and current philosophies and trends)

a professional engineering ethics and ethos

micro and macro ethical frameworks

- complex problems; risk and uncertainty

the new engineer and post-normal science.

\subsection{Wicked problem}

The principal assessment for this part of the module comprised a group assignment on a 'wicked problem'. The assignment aims to address the material covered in the module and the claim that artificial, oversimplified, well-defined problems and case studies often neglect 'the social complexities of engineering practice' (Bucciarelli, 2008).

The term 'wicked problem' was coined by Horst Rittel and Melvin Webber in a seminal paper where they described these as complex, messy problems where there is potential for disagreement in terms of their framing as well as around any proposed solutions (Rittel and Webber, 1973). Indeed, they suggest that 'it makes no sense to talk about "optimal solutions"" as "there are no "solutions" in the sense of definitive and objective answers' for a wicked problem. Nor can any proposed 'solution' to a wicked problem be tested, except through a pragmatic approach where interventions are made contingently and iteratively and experiential knowledge is gained. As such, wicked problems involve more than just the purely technical; they involve some societal aspect or interaction with people whereby context is fundamentally important. Technical solutions alone are therefore usually insufficient in tackling wicked problems; nontechnical and policy/value-based approaches are also required. Tackling them also requires collaboration, usually between stakeholders with different backgrounds, disciplines and experience, to help understand each others' positions or 'object worldviews' well enough to have intelligent dialogue about the different interpretations of the problem. This requires a new type of engineer, one who demonstrates 'increased reflexivity and broadened participation in how engineers define problems and attempt to solve them' and one who is equipped 'to deal with the dimensions of these challenges that are considered outside the "technical” realm' (Cech, 2012).

Two iterations of the wicked problem assignment form the basis of this study during successive years 2012-2013 and 2013-2014. Students were assigned to groups of five and invited to collectively choose a wicked problem from a list of about 30 . These include for example, problems on energy provision, water quality and provision, nanotechnology and nano-particles, traffic, sea level/flood protection, geoengineering, plastics, hazardous waste, food production, atmospheric carbon levels, local flooding events, chemical plant safety, nuclear power, road safety, artificial intelligence and electric power transmission.

They then are required to research the problem, consider the perspectives of different stakeholders and see how each might contribute to both the problem specification/description/ framing and how they might contribute to appropriate responses. Groups are also required to nominate a designated person whose formal role is to 'institutionalise doubt', a 'yes, but...' person who must act as a 'devil's advocate' and hence speak up, point out problems, critique suggestions, generate discussion, get the group to consider how worst-case scenarios might be dealt with, or consider different perspectives or (perhaps larger) windows on the world (Ulanowicz, 2009).

Groups were then invited to produce a report on their work and prepare a short $(7 \mathrm{~min})$ presentation to peers and the lecturing team, followed by a brief question and answer session.

\section{Student learning experiences and feedback}

The student learning experience and success in meeting the goals of the module were assessed through

reflective surveys

module feedback

student material presented as part of the wicked problem assignment.

\subsection{Reflective survey}

In 2012-2013 the survey was carried out after the module's completion. Of 125 students taking the module during 2012 2013, 73 responded, representing a 58\% response rate (Table 1; 13a). Part 1 of the survey sought to ascertain to what extent students embraced ideas presented in the module. To do this, students were asked which of two statements they most closely agreed with from each of seven statement pairs. The first of each pair represents a viewpoint that aligns with the dominant societal paradigm (seeking reduction, separation and control), which has characterised modern engineering (Herkert and Banks, 2012; Riley, 2008). The latter statement more closely aligns with what has been called a paradigm of complexity (Morin, 2008), and embraces inherent uncertainty, context and a broader macro-ethical framework (i.e. a focus on the broader context, e.g. the social, economic and political structures that engineering operates within, as well as values held by/across the profession) (Byrne, 2012a; Herkert, 2005) as permeates this part of the module. In 2012-2013 students were also asked to reflect and indicate whether (in their opinions, retrospectively) 


\begin{tabular}{lccccc} 
& $13 \mathrm{~b}$ & $13 \mathrm{a}$ & $14 \mathrm{~b}$ & $14 \mathrm{a}$ \\
\hline $\begin{array}{l}\text { Because engineers like to gather the facts from which the truth can be logically } \\
\text { determined, they are best positioned to solve many problems. }\end{array}$ & 17 & 6 & 43 & 4 \\
The 'truth' cannot be achieved through facts and logic alone; in fact, there are many & 36 & 67 & 35 & 66
\end{tabular}
possible legitimate truths within given frameworks - for example, different disciplines hold different perspectives and hence different truths.

\begin{tabular}{|c|c|c|c|c|}
\hline & $13 b$ & $13 a$ & $14 b$ & $14 a$ \\
\hline Engineering is largely (or exclusively) a value-free endeavour. & 14 & 6 & 14 & 2 \\
\hline \multirow[t]{2}{*}{ Values are inherent in all engineering practice. } & 43 & 67 & 64 & 68 \\
\hline & $13 b$ & $13 a$ & $14 b$ & $14 a$ \\
\hline $\begin{array}{l}\text { Improving efficiency is the key feature of good engineering - continually increasing both } \\
\text { technological efficiency and human productivity towards system optimisation. }\end{array}$ & 39 & 27 & 48 & 10 \\
\hline While efficiency is important for engineering, a sole focus on improving efficiency & 14 & 46 & 30 & 59 \\
\hline
\end{tabular}
represents poor engineering practice, as it reduces system resilience and redundancy while increasing tight coupling and risk

\begin{tabular}{|c|c|c|c|c|}
\hline & $13 b$ & $13 a$ & $14 b$ & $14 a$ \\
\hline $\begin{array}{l}\text { Basic scientific research is required as a precursor to technological innovation. * (*e.g. } \\
\text { as practised by engineers) }\end{array}$ & 38 & 20 & 30 & 18 \\
\hline Technological innovation* is often largely experiential and pragmatic and emanates from & 25 & 53 & 48 & 52 \\
\hline
\end{tabular}
ideas and creativity. Basic scientific knowledge, while potentially useful to this process is not necessarily a prerequisite ( ${ }^{\star}$ e.g. as practised by engineers).

\begin{tabular}{lrrrr}
\hline & $13 b$ & $13 a$ & $14 b$ & $14 a$ \\
\hline Engineers should be considered value-neutral 'guns for hire' or 'paid hands'. & 15 & 8 & 17 & 2 \\
Engineers should be committed to social good, thus bestowing privilege in some ways, & 38 & 65 & 61 & 68
\end{tabular}
while also conferring a level of responsibility for their work and its consequences.

\begin{tabular}{|c|c|c|c|c|}
\hline & $13 b$ & $13 a$ & $14 b$ & $14 a$ \\
\hline $\begin{array}{l}\text { Risk can be represented by objectively quantifying the likelihood of an incident } \\
\text { occurring. }\end{array}$ & 34 & 21 & 53 & 14 \\
\hline Risk is a social phenomenon and is culturally constructed; the likelihood of an & 18 & 51 & 25 & 55 \\
\hline
\end{tabular}
incident occurring is inherently subjective and thus in turn influences both the approach taken towards a risk and the risk level.

\begin{tabular}{|c|c|c|c|c|}
\hline & $13 b$ & $13 a$ & $14 b$ & $14 \mathrm{a}$ \\
\hline $\begin{array}{l}\text { When the general public oppose engineering projects, it is often due to scientific or } \\
\text { technical ignorance. It is therefore a key role of the engineer as experts to better } \\
\text { inform the public; we need to improve our communications. }\end{array}$ & 23 & 22 & 26 & 22 \\
\hline When the general public oppose engineering projects, it is often not due to inherent & 29 & 50 & 51 & 48 \\
\hline
\end{tabular}
scientific or technical ignorance, but because the project conflicts with inherent values, for example around ideas of wellbeing, community, acceptable risk. This requires a broader more participatory conception of engineering (the 'new' engineer).

Table 1. PE1006 reflective survey results (2012-2013 and 2013-2014) 
Engineering Sustainability

Volume 167 Issue ES6
Educating engineers to embrace

complexity and context

Byrne and Mullally the statement they supported represents a change from the view they held before they took the module. Of the 73 respondents, 53 indicated whether or not the module helped precipitate a change in their outlook (Table 1, 13b), with the remainder not indicating either way. In 2013-2014 students were surveyed on two separate occasions: just before the commencement of the module (Table $1 ; 14 \mathrm{~b}$ ) and upon its completion (14a). A total of 78 students responded to the first survey out of a cohort of 114 (a $68 \%$ response rate), while 70 responded to the latter $(61 \%)$. Any deviations from the above sum totals resulted from incomplete filling in of the forms.

Results of part 1 of the survey are presented in Table 1. A striking aspect of the results is the strong support for the second statement across each of the pairs of statements after the completion of the module (columns 13a, 14a). Another striking aspect is the degree to which students of the module over respective years came to very similar aggregated conclusions. In particular there was very strong support for the contention that different possible legitimate truths can exist within different frameworks, that values are inherent in engineering practice, and that engineers should be committed to social good. Intellectually at least, it would appear there is strong support among students of the module for the conception of engineering presented and a strong sense of social responsibility prevalent among first-year engineers. The module itself appears to have helped reinforce this significantly - as might be expected, given the tendency for intrinsic (greater than self) values, to be strengthened by exposure to them, and for the opposite to occur when extrinsic (selfish) values are portrayed (Burgoyne and Lea, 2006; Maio et al., 2009).

This is in fact strongest for the pair of statements which generated most division. Initially, a good majority of students each year would have at first agreed that efficiency was 'the key feature to good engineering', although this flipped around, particularly among the 2013-2014 cohort, who having taken the module were willing to adopt the more nuanced view which holds that while efficiency is important for engineering practice, a singular emphasis on this particular ratio means that system resilience and redundancy is reduced, while tight coupling and risk increases (i.e. essentially a singular focus on efficiency is potentially catastrophic as it reduces redundancy and resilience, hence curtailing system sustainability (Leach et al., 2010; Ulanowicz, 2009)). There were also large shifts in students' perceptions of risk, regarding it more as a social phenomenon (as opposed to an objectively quantifiable entity), and also on the basis for technological innovation, as well as on 'truth' as a function of framing and on public opinion being primarily based on inherent values rather than scientific ignorance. Taken together, these perceptions appear to indicate that students generally show a very positive disposition towards the ideas associated with the 'new engineer' whereby context, contingency and uncertainty are embraced. This resonates with a complexity/ contingent-based conception of sustainability (Ulanowicz et al., 2009), as opposed to a linear reductionist conception that more often pertains. While the latter envisages progress as a linear march towards some unique optimisation point through ever greater systemic order, control and efficiency, the former would conceive of progress as an emergent process emanating from a necessary contingent- and context-dependent dialectic balance between, on the one hand order and control, and on the other hand freedom, creativity and autonomy. This is essentially a worldview that envisages sustainability itself as

a discursively constructed concept without any stable definition and interpretation ... a heterogeneous and contested set of perspectives that are continually defined and redefined through social, cultural, and political practices. A central implication of this perspective is that sustainability cannot be viewed as a finite goal or destination we can work towards as a global community. Like the pot of gold at the end of the rainbow, sustainability is more of a moving target never quite to be reached. Using a navigational metaphor thus captures the concept more comfortably: sustainability discourses help us steer in a sea of future challenges and navigate around the rocky patches of undesirable solutions. (Petersen, 2013)

This approach is actually undertaken by many professional engineering practitioners who grapple with sustainability in the field, where by necessity 'more conflicted and complex' learning occurs amid 'contradictions and conflicts', as engineers

engage fellow stakeholders in the effort to give shape to sustainability in practice. The challenges involved reach beyond the technical to intrinsically human dimensions of sustainability that, in practice, become questions about issues such as organising stakeholder involvement, managing knowledge and negotiating commitments on action. (Laws and Loeber, 2011)

They also reject as inadequate the traditionally dominant approach to engineering education which seeks to strip away context. As Buch and Bucciarelli (2013) proclaim

the system is deficient. It is deficient because it ignores context - the context of practice, the context of use, the context of the individual psyche and the context that our culture provides - barely acknowledged in the teaching of engineering. We rarely explore or show how social and political interests contribute in important ways to the forms of technologies we produce.

A couple of points are pertinent in considering student responses. The module has no end-of-term exams (only continuous assessment exercises) and questionnaires were administered anonymously. Therefore, there was no compulsion on students to be coerced into new or different ways of 
Engineering Sustainability

Volume 167 Issue ES6
Educating engineers to embrace

complexity and context

Byrne and Mullally thinking or to provide answers that they might think would impress the lecturer. On the other hand, the reality of the power structure inherent in the system, whereby the lecturer may be viewed as a sort of fount of definitive knowledge is unavoidable. Even if/when other lecturers propose other potentially antagonising versions of 'definitive knowledge', this may be worn lightly by students as they can pragmatically flip-flop between different conceptions of reality, particularly given the structure of their programme is generally reductionist in the sense that it comprises a number of separate modules which combine to produce the degree, and apart from perhaps final-year capstone design or research projects, neither promotes nor requires an integrative approach to learning and teaching. One interpretation of this therefore might be that students, by virtue of the fact that they appear to be adept at accepting and wearing quite lightly whatever cluster of values are presented to them, may actually be less disposed to critical or independent thinking than they claim (see Section 3.2).

The second part of the survey was designed to see how students understood what had been covered in the module and see how their conception of the role of an engineer might now be, having just completed the module. It asked the following pair of open-ended questions (followed by a selection of responses).

Question 1. What is the single most relevant thing you have learned as part of this part of the module PE1006?

- That ethics and values are an inherent part of engineering and cannot be ignored. The concept of the 'new engineer'.

- Values are essential in the lives of engineers. Choices that engineers make cannot be based on scientific knowledge alone but also based on social, ethical and economic values.

- Engineering isn't just about thinking in a linear, mathematical way about problems. It must take social (and other) aspects into consideration.

- I have learned to look at problems in many different ways (i.e. there are very few problems with one specific solution. Each solution has problems within.)

- How risk can be thought of as a social phenomenon and how a perceived risk can affect people's actions.

- A wider range of thinking and consideration when seeking solutions to problems. There is no perfect solution to most engineering obstacles.

Question 2. What is the role of the engineer?

Help solve problems in society by innovative solutions, while taking into consideration society and likely reactions to such a solution.

- To utilise the resources available to man for the betterment of mankind.

- To provide a clear and logical solution to a posed problem.
- The role of the engineer is to use the forces of nature to better human life.

- Apply technical knowledge to solve social problems. While engineers work largely in a technical context, there is also a social responsibility.

To improve quality of life through science and technology, to innovate to find answers to modern-day problems and to bring solutions to life.

The responses to question 1 suggest that students took on board and saw as relevant many of the concepts covered as part of the module on issues around context, values, ethics, risk and the relationship between social and technical aspects of engineering. Question 2 on the role of the engineer elicited a more mixed response, however. Students appeared to struggle with incorporating the concepts they expressed in the previous question and in the earlier part of the survey into their conception of the role of the engineer. The responses shown above, which are representative of those presented, reverts to a conception of engineering that either mirrors the traditional self-perception of the engineer (deterministically controlling by way of technological solutions) or presents some muddled synthesis of the above alongside the ethos presented through the module. Thus, we get an engineer who is obliged to coerce all (sorts of) problems into a framework which will allow these to be heroically 'solved' using a toolbox that contains only technological tools: 'apply technical knowledge to solve social problems'. An hubristic notion that engineers can singlehandedly solve problems - even 'social' ones - and do this through science and technology appears to be prevalent. Moreover echoes of the modern Cartesian philosophy ('It is possible to reach a kind of knowledge which will be of the utmost use to men and thereby make ourselves the lords and possessors of nature' (Descartes, 1638)) abound: 'utilise the resources available to man for the betterment of mankind'; 'use the forces of nature to better human life'. Only the first response, which presents the role of the engineer in a broader, and more tentative and contingent light, appears to begin to grasp the import of the 'new engineer'. There thus appears to be a discontinuity of sorts; while formative engineers are prepared intellectually to accept a new and broader conception of engineering, they struggle to apply this meaningfully in terms of how this might affect the role of the engineer and in the practical application of engineering.

\subsection{Module feedback}

Feedback on the principal author's section of the module was garnered both electronically through UCC's Quality Promotion Unit (QPU) (2012-2013) and by hard copy, by way of the lecturer (2013-2014) following module completion. This survey elicited response rates of $48 \%$ (60/125) (2012-2013) and $61 \%$ (70/114) (2013-2014). While questions on the respective surveys differed, each survey had at least one 
Engineering Sustainability

Volume 167 Issue ES6
Educating engineers to embrace

complexity and context

Byrne and Mullally question that related to how this part of the module stimulated students' own perceived critical thinking and deeper learning/ understanding (Table 2). Between three-quarters and fivesixths of respondents agreed that the module precipitated enhanced stimulation of their thinking to an 'above average' extent or better; this result aligns with the relatively high proportion of students who claimed to have changed their perspectives by way of the module.

\subsection{Practical implementation by way of a wicked problem assignment}

The wicked problem assignment afforded students the opportunity to demonstrate the extent to which they could incorporate, in a practical way, many of the aspects covered in the module, and to which they generally claimed to ascribe. However, this proved to be a difficult exercise. One student alluded to this on the QPU survey when they commented: 'Very interesting, but also complex. It is just difficult to figure out how to EXACTLY start approaching wicked problems, but the principles and methods were made clear enough.' The student presentations appeared to reflect this, as students struggled to integrate the concepts they claimed to uphold in addressing reallife wicked problems. This resulted in a general lack of coherence and contradictory proposals, while in most cases groups ultimately proposed traditional reductionist 'solutions' to their respective problems, typically characterised by a singular drive towards ever greater efficiency. For example, one group in 20122013 looked at the problem of traffic and proposed that it could be solved by bigger, straighter and 'better' designed roads through signage, road markings, surface quality, flyovers and so on. At the same time, they recognised in their presentation that this approach does not look at 'the bigger picture' and may ultimately lead to increased traffic volumes. However, they offered no further or alternative proposals or insights. These findings are consistent with observations of Petersen (2013) in the context of developing a complexity informed 'contested discourses' view of sustainability, who suggests that

from this perspective it is no surprise that engineers have been struggling to deal with issues of sustainability. The traditional engineering approaches of setting up finite sets of goals or measures in order to develop tangible technologies to meet these goals are bound to fall short. Finite goals have no value when the desired destination is constantly changing - they will only result in redundant technological fixes without any significantly positive impact.

To try to address this issue, the 2013-2014 module iteration incorporated the aforementioned 2012-2103 student traffic presentation as a case study, whereby students were invited themselves to critique it and, in doing so, to reflect on how broader contextualised approaches might be applied. This was aimed at precipitating greater student reflections on the social complexities of traffic and attendant problem framings, such as by considering, for example, urban and suburban planning, the status of pedestrians, cyclist and public transport as well as other broader issues such as health and well-being, obesity, energy and fuel consumption. They were also asked to consider what are the ethical issues around their selected wicked problems as part of the assignment and hence to facilitate reflection more generally on 'what the social and ethical commitments of engineering are and ought to be' (Herkert and Banks, 2012).

While this may have improved students' engagement with the material, the 2013-2014 group presentations still suffered from a largely linear reductionist mindset where students still sought a unique optimisation. Moreover, and despite the formal imposition of a contrarian 'yes, but...' group member, most of the ultimate reports and presentations appeared to converge around some agreed group position. A lowest common denominator effect still seemed to be occurring, with little of the hoped-for creative tension or vision in evidence. This is problematic, in particular if one accepts that in relation to sustainability 'the power of the concept does not reside within such a shared understanding, but rather across the discursive field surrounding it' (Petersen, 2013). In response to this, the present authors suggest a greater emphasis might be placed on problem framing during future iterations, since this is a process which both opens up and closes down response possibilities (Leach et al., 2010).

\begin{tabular}{|c|c|c|c|c|}
\hline & Excellent & Above average & Average & Below avera \\
\hline \multicolumn{5}{|l|}{$2012-2013$ cohort $(n=125)$} \\
\hline $\begin{array}{l}\text { The stimulation to my thinking provided by this lecturer is: } \\
2013-2014 \text { cohort }(n=114)\end{array}$ & $21(35 \%)$ & $23(39 \%)$ & $11(18 \%)$ & $5(8 \%)$ \\
\hline $\begin{array}{l}\text { To what extent did this part of the module: } \\
\text {... help you develop new and deeper understandings you'd } \\
\text { previously overlooked or help broaden your perspectives? }\end{array}$ & $25(35 \%)$ & $33(48 \%)$ & $12(17 \%)$ & $0(0 \%)$ \\
\hline ...help make you think more critically? & $23(34 \%)$ & $34(49 \%)$ & $12(17 \%)$ & $0(0 \%)$ \\
\hline
\end{tabular}

Table 2. Post-module survey results on PE1006 (E. Byrne's section) 
Engineering Sustainability

Volume 167 Issue ES6
Educating engineers to embrace

complexity and context

Byrne and Mullally
Ideally, this would involve incorporating other disciplinary object world perspectives, such as for example, through engineers working with groups of social scientists to facilitate authentic trans-disciplinary creative tensions from which might emerge multi-scale, multi-faceted and/or multiple problem conceptions with resultant possible (albeit contingent and pragmatic) interventions. While this is not easily facilitated with a large group of first-year engineers, the authors have in fact initiated such collaborations at another level through bringing together students of respective third-year engineering and sociology modules around a common meta-theme of sustainability.

\section{Reflection}

Contemporary theories of learning support the idea that learning represents a personal journey whereby learners can be helped to continuously (re)construct their emergent conceptions of reality (Osberg and Biesta, 2007). In this context, engineers can be exposed to opportunities to explicitly (re)envisage their roles and responsibilities, including some of the dominant 'truths' that underlie engineering practice and contemporary society. However, even though people may intellectually accept certain values, paradigms or worldviews, this does not necessarily imply they will change their behaviour instantaneously, or even at all. There may be other conflicting values that are stronger and/or structural barriers to change in a wholly interconnected society (Hannan and Freeman, 1984). Peer pressure, groupthink and the desire to fit in too are extremely powerful human drivers. But to paraphrase the oft-quoted economist Rudiger Dornbusch, change, just like 'crisis takes a much longer time coming than you think, and then it happens much faster than you would have thought' (Dornbusch, 1995).

The experience with this module is that while students are willing to explicitly accept a worldview which recognises indeterminacy and complexity, and while they claim to recognise the professional importance of understanding concepts such as context, uncertainty, complexity and ethical sensitivity (Byrne, 2012b), they nevertheless struggle to implement this in practice, as they operate within a world(view) which consistently and determinedly tells them otherwise. Students clearly struggled to 'join the dots' when faced with the key but difficult task of practical implementation. This is perhaps unsurprising as, when faced with a challenge of implementation in any learning process, it is easier to revert to type (i.e. previously held, more deeply embedded constructs of reality) on being presented with a new and significant challenge. Moreover behavioural change in response to changes in people's environmental circumstances is typically non-linear, often following a non-linear 'zigzag course' (Hernes, 2012).

\section{Conclusion}

A new kind of engineer is required if engineering is to be fit-forpurpose to address twenty-first century sustainability-related challenges. Such an engineer challenges current paradigmatic reductionist thinking (Ehrenfeld, 2008; Ulanowicz, 2009) and requires a broader, more contingent view of professional engineering roles and responsibilities while taking a broader (context and complexity informed) view that embraces the transdisciplinary approach necessary to address emergent 'grand challenges' pertaining to issues around sustainability which straddle multiple interconnected (environmental, social, economic) domains (Reid et al., 2010). The self-perception of such an engineer goes well beyond one whose only tool in their toolbox is technology and whose default approach is to seek increased control through enhanced efficiency and productivity. Communications and transportation system design, for example, need to utilise technology efficiently, but a one-dimensional engineer who cannot relate to the social implications is one who merely serves to contribute to deeper and more widespread 'unintended' consequential problems associated with and driven by emergent technologies. A key intervention point in the precipitation of a broader fit-for-purpose profession is through its formative professional education. Undergraduate engineers require exposure to contemporary knowledge and research around the nature of complexity, uncertainty and ethics to provide them with the opportunities to be equipped with the necessary tools to embrace and facilitate meaningful societal transformation, and to be equipped to do so in concert with other disciplines and extended peer groups. This work has examined a module which has sought to help develop such an approach, reflected on some challenges that arose, and has proposed some suggestions that can assist in meeting these challenges.

\section{REFERENCES}

Baillie C, Reader J and Kabo J (2013) Heterotopia: Alternative Pathways to Social Justice. Zero, London, UK.

Beder S (1998) The New Engineer. MacMillan, New York, USA. Boud D (2000) Sustainable assessment: Rethinking assessment for the learning society. Studies in Continuing Education 22(2): 151-167.

Bucciarelli LL (2008) Ethics and engineering education. European Journal of Engineering Education 33(2): 141-149.

Buch A and Bucciarelli LL (2013) Getting context back in engineering education. Proceedings of a Conference on Engineering Education for Sustainable Development EESD13, Cambridge, UK.

Burgoyne CB and Lea SEG (2006) Money is material. Science 314(5802): 1091-1092.

Byrne EP (2012a) Teaching engineering ethics with sustainability as context. International Journal of Sustainability in Higher Education 13(3): 232-248.

Byrne EP (2012b) Enhancing engineering employability in the 21st Century; handling uncertainty and complexity through 'new entrepreneurship'. Proceedings of the 4th International Symposium for Engineering Education ISEE2012, Sheffield, $U K$. 
Cech E (2012) Great problems of Grand Challenges: Problematizing engineering's understanding of its role in society. International Journal of Engineering, Social Justice, and Peace 1(2): 85-94.

Conlon E (2008) The new engineer: between employability and social responsibility. European Journal of Engineering Education 33(2): 151-159.

Descartes R (1638) Discourse on Method, Part 6. Translated by Clarke DM (1999). Penguin, London, UK.

Dornbusch R (1995) Frontline interview. See http://www.pbs. org/wgbh/pages/frontline/shows/mexico/interviews/ dornbusch.html (accessed 09/05/2014).

Ehrenfeld JR (2008) Sustainability by Design: A Subversive Strategy for Transforming Our Consumer Culture. Yale University Press, New Haven, CT, USA.

Fitzpatrick JJ, Byrne EP, Ring D et al. (2013) Evolving aspects of sustainability in a chemical engineering capstone design project. Proceedings of the Engineering Education for Sustainable Development 2013 Conference (EESD'13), Cambridge, UK.

Hannan MT and Freeman J (1984) Structural inertia and organizational change. American Sociological Review 49(2): 149-164.

Herkert JR (2005) Ways of thinking about and teaching ethical problem solving: microethics and macroethics in engineering. Science and Engineering Ethics 11(3): 373-85.

Herkert JR and Banks DA (2012) I have seen the future! Ethics, progress, and the Grand Challenges for engineering. International Journal of Engineering, Social Justice, and Peace 1(2): 109-122.

Hernes G (2012) Hot Topic - Cold Comfort Climate Change and Attitude Change. NordForsk, Oslo, Norway.

Laws D and Loeber A (2011) Sustainable development and professional practice. Proceedings of the Institution of Civil Engineers - Engineering Sustainability 164(1): 25-33.

Leach M, Scoones I and Stirling A (2010) Dynamic
Sustainabilities: Technology, Environment, Social Justice. Earthscan, Abingdon, UK.

Maio GR, Pakizeh A, Cheung WY and Rees KJ (2009) Changing, priming, and acting on values: effects via motivational relations in a circular model. Journal of Personality and Social Psychology 97(4): 699-715.

Morin E (2008) On Complexity. Hampton Press, New York, NY, USA.

Mulder KF, Segalàs J and Ferrer-Balas D (2012) How to educate engineers for/in sustainable development: ten years of discussion, remaining challenges. International Journal of Sustainability in Higher Education 13(3): 211-218.

Osberg D and Biesta G (2007) Rethinking schooling through the 'logic' of emergence: some thoughts on planned enculturation and educational responsibility. In Complexity Science and Society (Bogg J and Geyer R (eds)). Radcliffe, London, UK, pp 35-39.

Petersen RP (2013) The potential role of design in a sustainable engineering profile. Proceedings of a Conference on Engineering Education for Sustainable Development EESD13, Cambridge, UK.

Reid WV, Chen D, Goldfarb L et al. (2010) Earth system science for global sustainability: Grand challenges. Science 330(6006): 916-917.

Riley D (2008) Engineering and Social Justice. Morgan and Claypool, San Rafael, CA, USA.

Rittel H and Webber M (1973) Dilemmas in a general theory of planning. Policy Sciences 4: 155-169.

Ulanowicz RE (2009) A Third Window: Natural Life Beyond Newton and Darwin. Templeton Foundation Press, West Conshohocken, PA, USA.

Ulanowicz RE, Goerner SJ, Lietaer B and Gomez R (2009) Quantifying sustainability: Resilience, efficiency and the return of information theory. Ecological Complexity 6(1): 27-36.

\section{WHAT DO YOU THINK?}

To discuss this paper, please email up to 500 words to the editor at journals@ice.org.uk. Your contribution will be forwarded to the author(s) for a reply and, if considered appropriate by the editorial panel, will be published as discussion in a future issue of the journal.

Proceedings journals rely entirely on contributions sent in by civil engineering professionals, academics and students. Papers should be 2000-5000 words long (briefing papers should be 1000-2000 words long), with adequate illustrations and references. You can submit your paper online via www.icevirtuallibrary.com/content/journals, where you will also find detailed author guidelines. 